\title{
The Epidemiology of Indonesian Children and Adolescent School-based Mental Health: Validation of School-based Mental Health Information System
}

\author{
Amitya Kumara*, Supra Wimbarti, Yuli Fajar Susetyo, Ammik Kisriyani \\ Faculty of Psychology, Universitas Gadjah Mada, Indonesia
}

Copyright $(2017$ by authors, all rights reserved. Authors agree that this article remains permanently open access under the terms of the Creative Commons Attribution License 4.0 International License

\begin{abstract}
Every year, 20\% of teenagers at school suffer from common mental disorders such as anxiety and depression (WHO, 2011). Indonesian Health Ministry reported that the prevalence of emotional disturbance of students at age 15 year and above is about $6 \%$ (Riset Kesehatan Dasar, 2013). This fact above reaffirms the importance of school-based mental health as a strategic program to elevate adolescent well-being. This study specifically aims to validate mental health screening and diagnostic instrument to collect more accurate and comprehensive data about children and adolescents' mental health state and manage it using Integrated Mental Health Information System (Sistem Informasi Kesehatan Mental/SIKM). The participants in this study were 308 students consisted of elementary school, middle school, high school students, and 28 teachers in Yogyakarta. Data collection was conducted through online survey using mental health scale and knowledge questionnaire. Additional data was collected through interview and focus group discussion. The data shows that students' mental health state in Yogyakarta belonged to moderate category (81\%) and high $(19 \%)$. Focus group discussions revealed no system and policies have established to support students' mental health at schools. Generally, according to assessment done by the teachers, the level of students' well-being was described as such: $10.71 \%$ belonged to high category, $75 \%$ moderate, and $14.28 \%$ low. These findings provide early data to determine appropriate intervention programs in the future.
\end{abstract}

Keywords School-based Mental Health, Mental Health Information System, Students' Well-being

\section{Background}

Recently Indonesia has a critical mental health issue regarding various reports in the media about of bullying, sexual violence, brawls, suicide, and even murder. Some cases of sexual harassment experienced by the kindergarten children at an international school in Jakarta left the victim with deep trauma (Kompas.com, April 17, 2014). Child abuse is only one among others. In other region, an elementary school student committed to suicide due to an intense fear caused by the homeroom teacher who threatened the class with punishment if they did not behave well (Radar Lampung, 8 November 2013). The absenteeism has been becoming a major academic problem for adolescents these past few years. The municipal police officer revealed that 14 junior high school students skipped from their school in the midst of truant in a region of Central Java province (www.krjogja.com/-, September 2013). The Commission of Child Protection of Indonesia stated that there were 229 cases of student brawls which resulted in 19 mortalities. The number of brawls was higher than the previous year which had 128 cases (Tribun Jogja, 21 November 2013). It can be seen that there is a massive number of brawls as the number of cases has increased by almost $100 \%$.

Beside the issues reported by the mass media, many research reported other issues regarding teenage behavior problem such as smoking and alcohol consumption. Riset Kesehatan Dasar (2013) recorded that $0.5 \%$ of children within the age group of 10-14 years old smoke daily, while the percentage of those who smoke occasionally is $0.9 \%$. Meanwhile, in the age group of 15-19 years old, $11.2 \%$ smoke daily and $7.1 \%$ were occasional smokers. Joint research conducted by Center for Public Mental Health (CPMH) Universitas Gadjah Mada, PMI, Norwegian North Cross and International Federation and Red Cross Red Crescent Societies in Central and East Java (2011) has also recorded the negative behavior of Senior High School Students, both in general and vocational schools. The data showed that almost $10 \%$ students smoked, almost 35\% tried to smoke, almost $10 \%$ consumed alcohol, and about $10 \%$ tried to consume alcohol.

The problem is also reflected in the case of girls who give birth at very young age. Indonesian health Ministry reported that the percentage of teenage who gave birth in young age 
( $15-19$ years old) is $1.97 \%$, and younger ages $(<15$ years $)$ is 0.02\% (Riset kesehatan Dasar, 2013).

In a state where $40 \%$ of the entire population consists of children, Indonesia has to take these issues into account seriously. Childhood and teenage, as a highly respect of important stage for the human development, are not immune to the risks of both physical and mental health problems. Mental and physical health is two interconnected aspects which are important in building the prosperity of a society. The World Health Organization (WHO) defines the concept of health as a thriving physical, mental and social condition, not simply the absence of disease and weakness. This concept of health broadens its meaning into well-being, happiness, satisfaction, and quality of life (WHO, 2003).

The well-being, satisfaction and quality of life of children and teenagers are naturally highly susceptible by conditions and the influence of the environment, in which the child or teenager lives, including the family environment, school, and social environment. As the children and teenagers spend about 6-8 hours in a school environment, the participation of school authorities is highly important in promoting their mental health. The Constitution of Indonesia Number 20 Year 2003 (UU Republik Indonesia No 20 tahun 2003 tentang Sistem Pendidikan Nasional) states that education in Indonesia is not only aimed at developing the academic potential of the students. It is mentioned in Article 3 that:

National education functions to develop the capability and shape the characteristics and civilization of a dignified nation by enhancing the life of the nation, aiming to develop the potential of students to become members of the society who are faithful to God, noble, wise, competent, independent, as well as a democratic and responsible civilian.

As stated above, the involvement of school authorities is highly needed due to the fact that conditions in the school highly affect the psychological condition of the students. Therefore, information regarding psychological conditions must become essential for taking further mental health promotion and intervention program.

Finally, promoting and giving intervention of mental health problem at schools need a systematic and integrated system which can give information to the authorities as a basic data. This research is a first step of a big research of The Epidemiology of Indonesian Children and Adolescent School-based Mental Health. This first step is building School-based Mental Health Information System. The study will hopefully be able to be applied on the basic step of prevention and control program in addressing mental health problems.

\section{Literature Review}

\subsection{Mental Health at School}

School-aged children spend nearly half of their days at school. For some, going to school does not always mean going with minimum struggle. They might face trouble in understanding the lessons given by the teacher or in getting along with their classmates. Every child and adolescent must be able to manage their emotions, behaviors, and problems at home so that they do not manifest into an even bigger trouble at school and hinder them from learning and adjusting (Kumara, 2012; Kumara et.al. 2013; Christner\&Mennuti, 2009).

WHO (2003) reported a high rate of mental disorder cases during early childhood, such as Learning Disorders (LD) Attention Deficit and Hiperactivity Disorder (ADHD); and Tourette syndrome in middle age children (middle childhood). Research conducted by Wimbarti and Purwantini (2013) in Yogyakarta found that many children of primary school age still expressed difficulty in learning mathematics, especially conversion. Problems that occur in teenagers include depression and suicide attempt, psychosis, pervasive development disorder, attachment disorder, anxiety disorder, conduct disorder/ anti-social personality, substance abuse, and eating disorders. This problem had a heavy impact on the handling of special needs students in the school and obviously the high cost of treatment, just as Scott (2002, WHO, 2003) reported that the cost for the handling of children with conduct disorder increases overtime. Similarly, in the case of ADHD, Leibson et.al. (2001) also conveyed that the costs for the treatment of children with ADHD are more than twice that of normal children in general.

School is often times the closest environment a child can have. In this microsystem, an individual interacts directly with social agencies, with peers or teachers (Santrock, 2003). The success stories of children and teenagers who excel in school and win various national and international competitions are frequently heard too. This illustrates that conducive school environment does play a part in the development of children's achievement (Kumara, 2012). In general, these conditions represent two contradictory sides of the world of our schooling system. On one hand, school can be a supportive environment for the optimal development of children and adolescents. However, on the other hand, school can also be a cause of emotional and behavioral problems in children and adolescents students (Kumara, 2012).

This understanding gives the sense that the discussion about mental health has moved on from just talking about mental disorder to an actual discussion about how individuals can actualize themselves. Mental health does not only mean the absence of risks and problems that affect the psychological wellbeing of children, but also about how to encourage positive factors in their lives that can support positive developments (Morrison \& Kirby, 2010 cited in Singh \& Junnarkar, 2015). According to Keyes (2003), empirically, mental health and mental disorders are not seen as the opposite ends of a continuum. Schools have an important role in driving the mental health of students, as they spend much of their life at school. Wells, Barlow and 
Steward -Brown (2003) explained that the school-based mental health promotion must be implemented with different approaches. Mental health is described by WHO (2003) as a situation where every individual realizes their own potentials, can cope with the pressures of life, can work productively and is able to make a contribution to society. This definition becomes the basis of mental health measurement in this study, in which subjective well-being, coping strategy, and academic self-efficacy, and adjustment skills.

\subsection{Student Mental Health Screening Instrument}

In relation with the mental health screening, Richard, Lussier, Gagnon, and Lamarche (2004) mentioned that detection on population at an increased risk of mental health disorders is an important step in mental health prevention programs. In this case, the use of screening instruments as a tool for detecting mental health disorders may increase the information of identification of the people that require further evaluation and high risk (Boyd, Le, \& Somberg, 2005).

According to WHO (2004a), mental health information system is a system purposively to collect, process, disseminate, and use information about mental health services of the community. The main purpose of this system is to improve the effectiveness and efficiency of mental health services across the school environment. School-based Mental Health Information System, named Sistem Informasi Kesehatan Mental (SIKM), therefore is expected to improve service delivery to the public so that it can be more evenly distributed. This can be achieved by empowering the system administrator community mental health services, as well as service providers, in making decisions related to improving the quality of mental health services, on the basis of reliable information. SIKM will then be placed within the framework of achievement of these objectives. In other words, SIKM is made not only to collect data but also to enable the authorities to make a decision related to the mental health system that is based on reliable information.

The essence of this SIKM certainly is information obtained from the stakeholders as the data. The process of transforming data into information has to pass through a number of stages. The first is the collection of data from information sources in the system of mental health services. The results of the analysis of data are then submitted to the parties concerned, in the form of information that can be used for decision making. The use in the decision making process related to the improvement of services, planning, development and evaluation of the program is the main objective of disseminating information sourced from SIKM.

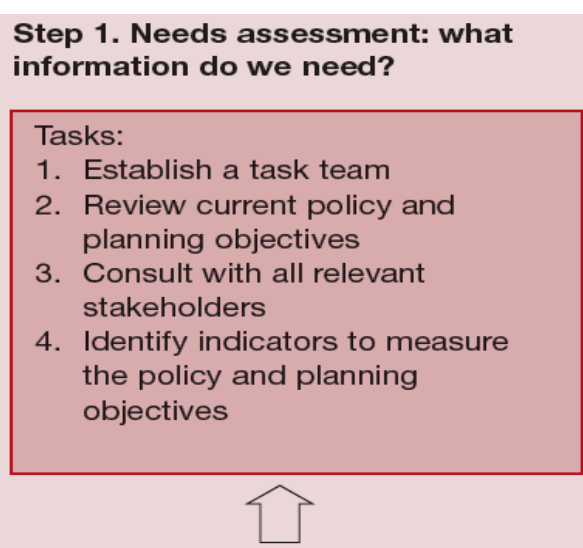

Step 4. Evaluation: how well is the MHIS working?

Tasks:

1. Establish criteria for evaluating the MHIS

2. Establish a framework for evaluating the MHIS

3. Compare with baseline data

4. Determine the frequency of the evaluations
Step 2. Situation analysis: what information do we have?

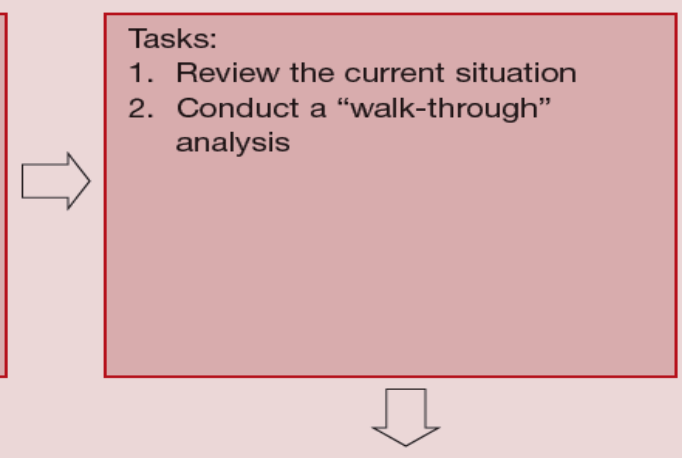

Step 3. Implementation: how can we get the information we need?
Tasks:
1. Identify the essential MHIS subsystems and indicators
2. Establish the minimum data set
3. Map the information flow
4. Set a time line
5. Identify roles and responsibilities
6. Design and distribute materials
7. Schedule staff training
8. Address practical barriers to getting the needed information
9. Build in quality checks
10. Conduct a pilot project
11. Roll out the MHIS

Image 3. Steps in Developing Mental Health Information System (Source: WHO, 2004, page. 35) 


\section{Objectives}

The main objectives of this research are:

1. To assess current condition and policy about school mental health information system

2. To validate screening instrument of students' mental health status in schools.

3. To try-out the mental health information system

The benefits derived from this research are helping various parties to map the students' mental health status in schools by using an integrated screening instrument in SIKM.

\section{Research Method}

The method used in this research is quantitative which was collected from the survey. The qualitative data were collected as a part of initial assessment to the stakeholders. Epidemiological study can be defined as the study of distribution, determinants, and health-related conditions or events in specific populations. The target for the first year of this study is to find the index number of mental health in schools. With the discovery of the index, the prevalence data can be found in the next stages of research.

\subsection{Participants}

The participants in this study are students and teachers at several schools in Yogyakarta ranging from elementary school to high school. The sampling method used is clustered purposive sampling. The distribution of research subjects is as follows:

Table 1. Research Subjects

\begin{tabular}{|c|c|c|c|}
\hline No & Grade & Number of Students & $\begin{array}{c}\text { Number of } \\
\text { Teachers }\end{array}$ \\
\hline 1 & Elementary School & 89 & 12 \\
\hline 2 & Middle School & 116 & 4 \\
\hline 3 & High School & 103 & 12 \\
\hline & & 308 & 28 \\
\hline
\end{tabular}

Based on Indonesian Central Bureau of Statistics (BPS, 2010), the population of children age 7-12 (elementary school age) was 29.127; age 13-15 (senior high school age) is 15.569; and age 16-18 (senior high school age) is 16.441. The total population on those is 61.137 . The sample of this study is 308 students. By using $90 \%$ confident level, the margin of error is $5 \%$. Population can be assumed as a unified whole and not separated per level for data analysis and determination of the index, because all respondents from various levels will still get the same scale. Therefore, the margin of error for each level can be ignored. Although the sample did not meet statistical standard, it was still considered good as it was selected purposively. So the margin of error can be considered as an input of confidence in the data only, not as a benchmark sampling.

Besides involving 308 students, this study was also involving 28 teachers. The teachers were ask about the condition if the mental health status of students in their schools.

\subsection{Measurement}

The preparation of the measurement instrument used in the research was done through the process of determining the conceptual definition of mental health. In this case, the conceptual definition used is the one defined by WHO (2003), in which mental health is where every individual realizes their own potentials, can cope with the pressures of life, can work productively and is able to make a contribution to society. This definition then is broken down into four dimensions, that later serve as the base for School Based Mental Health Scale:

\section{Subjective well-being}

It consists of the following aspects from Diener and Ryan (2009): (1) life satisfaction, and positive \& negative effect. The scale has 26 items in total.

\section{Coping strategy}

It is derived from Lazarus and Folkman (1984). Its aspects concluded in the scale are focused coping and emotional focused coping, with 14 items in total.

\section{Academic self-efficacy}

Bandura's concept of self-efficacy is applied to generate 11 items that consist of magnitude, generality, and strength aspects (1997).

\section{Adjustment skills}

This dimension uses Baker and Siryk's (1989) concept of adjustment skills in terms of academic life and contains 11 items. It includes four aspects:

a Academic motivation; the attitude and motivation toward academic goals and tasks

b Academic application; the extent to which the motivation displayed in actual academic effort or ability to meet students' academic needs

c Academic performance; the satisfaction of the academic function

d Satisfaction of academic environment

The additional data collection is done by the following measuring instruments:

1. Questionnaire on Students Strength and Difficulties (Strength and Difficulties Questionnaire (SDQ)

The questionnaire is adapted from SDQ, which reveals the strengths and difficulties of children. All versions of SDQ consist of 25 items that describe the positive and negative attributes of children and adolescents. They are allocated into five subscales; each is composed of 5 items: (a) the emotional symptoms subscale, (b) the conduct problem subscale, (c) hyperactivity/ inattentive subscale, (d) relationship problems with peers, and (e) prosocial behavior (Wimbarti \& Oktaviana, 2014; Wimbarti \& Siregar, 2014)

2. Knowledge Questionnaire Teachers of Children with Special Needs

This questionnaire is intended to determine the teacher's knowledge of the characteristics of children with special needs. It consists of 72 items including 
characteristics of special needs which are divided into cognitive, behavioral aspects, emotional aspects and social aspects.

3. Scale perception of teachers to student wellbeing

The scale is developed to determine the perceptions of teachers on student wellbeing. This scale consists of 15 items, which includes teacher perspectives on aspects of life satisfaction, positive affect and negative affect associated with students.

In this study, after testing the instruments, they all were inputted into the website, which is SIKM. The website is then accessed by every research subject. To help fill the measuring instrument, researchers have already prepared a manual to input data onto mental health information system. This site can be accessed through the address sikmsekolah.psikologi.ugm.ac.id.

This website is also intended to support promotional measures of school-based mental health that is able to be accessed publicly by all those in need.

\section{Results and Discussion}

\subsection{Objective 1: To Assess Current Condition and Policy about School Mental Health Information System}

To assess current condition and policy about school mental health information system, the Focus Group Discussion was done by involving policy makers. They are school headmasters, the head of local authorities in education, and the staff of education agency. According to the policy makers, they actually need to have a systematic system to get appropriate students' mental health status, but they have not had that system yet. This information is needed in building the SIKM for the first step about current policy.

The second step if the mental health information system building is figuring out the current condition of mental health. This current condition is drawn by the teachers who work for school counselor and the students.

The teachers who work as students counselors were involved through FGD. They stated that the problems occurred among students are about personal problems (cognitive, affective, and behavior), social interaction, and other contextual problems that is influenced by school conditions. The problems varied from the adaptation problem, gang, inferiority, and academic problems. The mental health service is around serving the students who came into counselor offices. Generally, there have not been neither comprehensive nor standard program about mental health at schools. The teachers support the idea of building integrative School-based Mental Health Information System or SIKM. The teachers committed to be involved in the school based mental health information system.

Findings from a survey data from 237 students in several primary and secondary schools in Yogyakarta on May and June 2015, which are related to mental health problems, revealed that the problems faced by the students are dominated by emotional issues such as: feeling angry and cranky, uncontrollable fear, drastic mood swings, and exaggerated anxiousness. The students feel as if they were unable to be themselves and occasionally had the urge to self-harm, anxious, and unable to organize themselves. Additionally, behavioral problems were the urge to break the rules, relationship problems with the opposite sex, and purposefully acting out for the sole reason to attract attention. There were specific problems related to the school, which were experienced by the students. For instance, low motivation to study, a decreasing trend in their academic performance, and difficulty to concentrate in their studies. This information is also the needed data for $2^{\text {nd }}$ step of the mental health information system building as current information of mental health status.

From the data above, it could be concluded that the School-based Mental Health Information System is necessary. It is because the school plays an important role as the formal and legal institution to run a systematic mental health promotion and intervention program. Operationally, the school may be involved in gathering the data of students' mental health status, then the data will be integrated with the stakeholders and will be analyzed to make a decision for school and policy makers in building mental health promotion and intervention program.

\subsection{Objective 2: To Validate Screening Instrument of Students' Mental Health Status in Schools}

\section{Mental Health Scale Validation}

The Mental Health Scale consist of four dimensions; subjective well-being, coping strategy, academic self-efficacy, and self-adjustment. Reliability test results of this scale is 0.903 from 62 items. Item number 63 was disqualified due to errors in data retrieval.

\section{Subjective well-being scale}

Subjective well-being scale, which consists of 26 items, has optional responses ranging from very appropriate to very not appropriate. From the tryout result, the reliability of this scale is 0,861

\section{Coping Strategy scale}

Coping strategy scale consisted of two dimensions, those are problem-focused coping and emotional-focused coping, has 14 items. The reliability of this scale is drawn by alpha coefficient of 0,614.

\section{Academic Self Efficacy Scale}

This scale consisted of three dimensions (magnitude, generality and strength) has 11 items. The reliability of the scale was shown by alpha coefficient of 0,614 .

\section{Self-Adjustment Scale}

This scale consisted of four dimensions (academic motivation, academic application, academic performance, and satisfaction of academic environment) has 11 items. The alpha coefficient of this scale is 0,741

Large-scale test is done through a two-stage filtration. The results of this test were an index and items that had been selected. Selection of items is needed to be done to determine 
whether the scale was reliable and compact enough to be carried out online.

The first scale was tested using PASW 18 by exploratory factor analysis. Items selected to be tested in the second phase of the analysis were with a coefficient factor above 0.3 and were in factor 1 . This analysis got 50 items that could fit into a factor of 1 .

Fifty items obtained were then further tested using the Rasch model of Winsteps 3.73 to find their discrimination and distribution index. This model could be utilized to find out whether a particular item has the ability to reveal differences between groups of respondents with high total score and respondents with lower one.
Another selection phase through professional judgment was conducted to make the scale even more condensed. Items with tied, overly high and overly low discrimination index were considered redundant and eliminated. At the end, 32 items with score ranging from $0-100$ were selected. The score of the index was 48.5030, with a standard deviation of 7.4963. The cronbach alpha reliability value of the scale was 0.890 . The lower value was not a problem because as it remained in the high range. To ensure the reliability of the real scale, re-collection of data in the future is necessary.

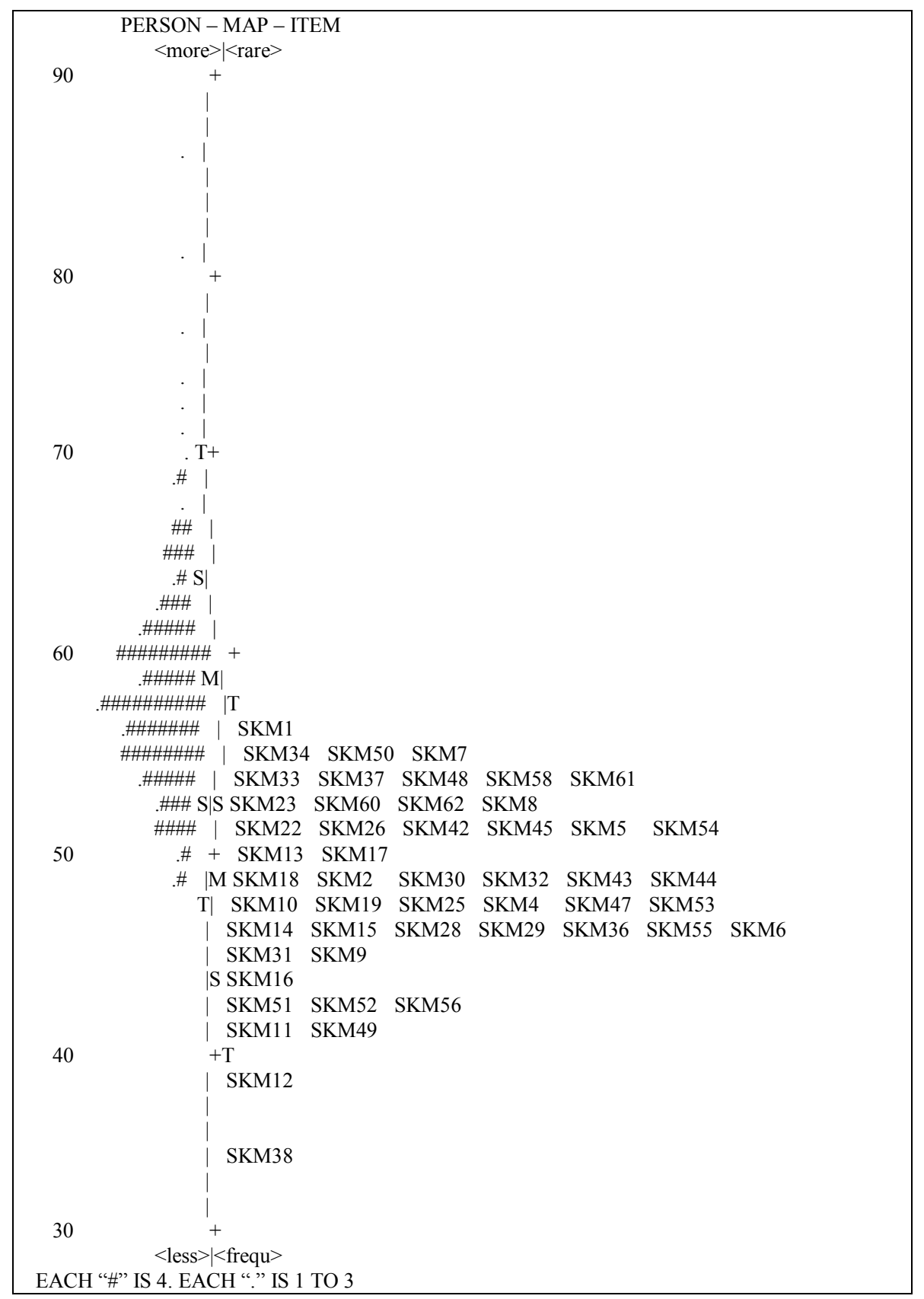

Item Map of Mental Health Scale 


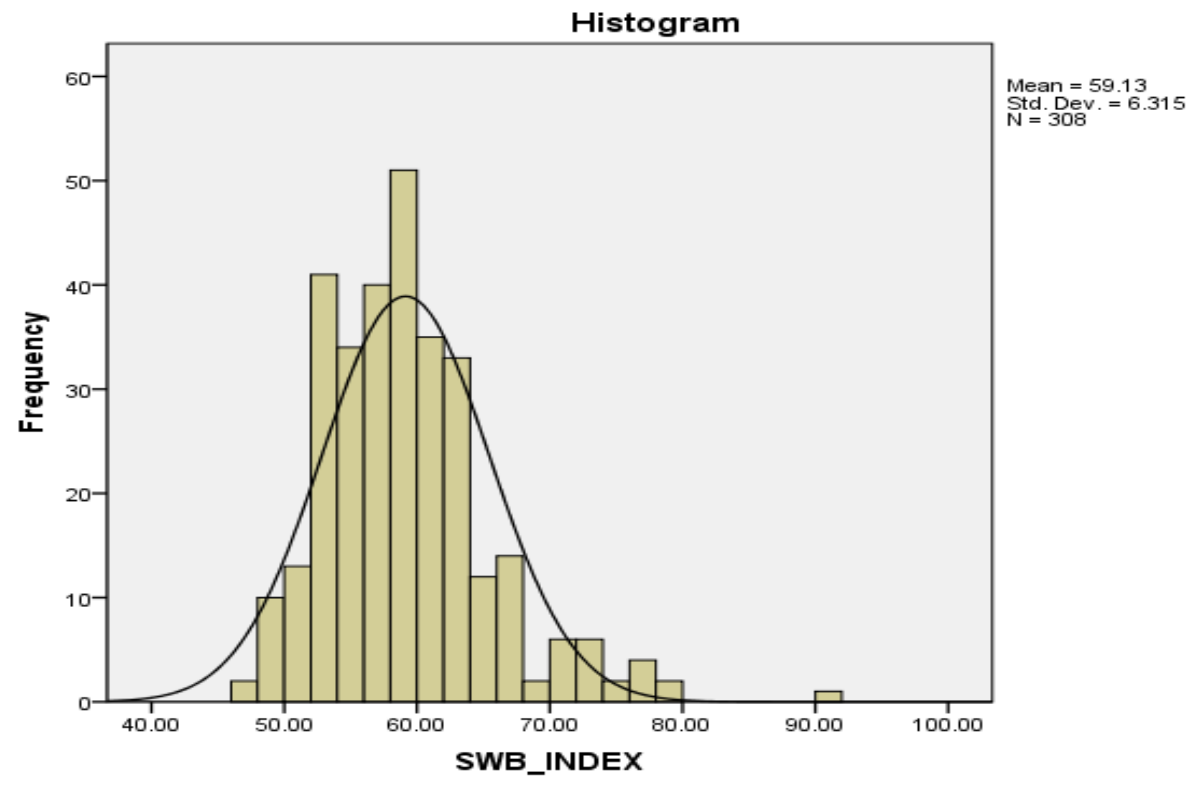

Figure 2. Histogram of Mental Health Index

\subsection{Objective 3: To Try-out the Mental Health Information System}

The graph above depicts the distribution of mental health score of the 308 participants. None of the students falls into the low category in this measurement. More problems were found in children with medium Mental Health Index scores compared to those with high index scores. The data shows that $81 \%$ participants are in moderate level and $19 \%$ participants are in high level.

Table 1. Mental Health Score Distribution

\begin{tabular}{|c|c|c|}
\hline \multicolumn{3}{|c|}{ Mental Health Score Distribution } \\
\hline & N & Percentage \\
\hline High & 57 & $19 \%$ \\
\hline Moderate & 251 & $81 \%$ \\
\hline Low & 0 & $0 \%$ \\
\hline
\end{tabular}

\subsection{Instrument 2: SDQ}

28 teachers from elementary school, junior high school, and senior high schools were asked to assess the students' well-being. They perceived that students' well-being are $75 \%$ in moderate category, $10,71 \%$ in high category, and $14,28 \%$ in low category.

\subsection{Discussion}

In accordance to one of the purposes of this research, which is to acquire a valid instrument of mental health screenings for students, this research has acquired a means of screening by the name of Skala Kesehatan Mental (Mental Health Scale) which made up of 32 items. This scale has reliability of alpha cronbach 0.890 . As explained by Richard, Lussier, Gagnon and Lamarche (2004), it is vital to detect individuals who may have a risk of experiencing mental disorders, so that the correct steps for intervention can be performed. The discovery of a measuring instrument for mental health towards this research will aid in the efforts to detect mental disorders, especially within a school setting.

In relation to the index of mental health, based on the of data analysis there are $81 \%$ participants fall into the category of average mental health, and $19 \%$ belong to the category of good mental health. In general, this data shows that mental health conditions in students during the time of primary, middle and high schools are in a decent condition. However this data becomes an early warning indicator of mental health problems in schools. The majority of the participants of this research belong to an average or medium mental health.

Findings acquired from questionnaires filled in by the students also show that this condition is in line with the findings that generally there is still a potential in each class that there is a child with emotional issues, behavioral issues, and problems with their peers. The issue of emotion is expressed by anxiety, unhappy and hopeless feelings, fear of new situations and lack of self-esteem. Behavioural issues take the form of children being unable to control themselves, fighting, stealing, being disobedient and cheating. Issues involving peers include not having close friends, not being received well by their peers, experiencing negative treatment from peers and a tendency to be alone. These findings follow along the sentiment of the first survey which has shown that mental illnesses are dominated by aspects of emotional problems such as being angry for long periods of time, uncontrollable fear, drastic mood swings, and exaggerated anxiety. Meanwhile, cognitive issues include the feeling as if they are unable to be themselves, the urge to self-harm, 
anxiety, and the inability to organize themselves. Next are behavioural problems including the urge to break rules, regulate behaviours with the opposite sex, and purposefully acting out for the sole reason of attracting attention. Lastly are the problems specific to school that are experienced by the students, including low motivation to study, a decreasing trend in their academic performance, and difficulty concentrating on their studies.

Acquiring data online is considered to be sufficiently effective. Manual directions given to the students are often not given attention; however the filling of data can still run smoothly. In data gathering process, when the students were asked to fulfill the questionnaire, there were several assistants to help the operation if the participants faced a problem in using the website. Nevertheless, the participants did not ask the assistants to help them. This indicates that interface from the SIKM site is user-friendly, so that special instructions are not needed in order to use it. The target to make a comprehensive manual is not needed for students.

\section{REFERENCES}

[1] Baker, R.W., \& Siryk, B. (1989). SACQ: Student adaptation to college questionnaire emanual. Los Angeles: Western Psychological Services.

[2] Bandura, A. (1997). Self-Efficacy. The Exercise of Control. New York: W.H. Freeman and company

[3] Boyd, R.C., LE, HN., Somberg, R. (2005). Review of screening instruments for postpartum depression. Arch Sep; 8(3):141-53.

[4] Christner, R.W. \& Mennuti,R.B. (2009). School-Based Mental Health. New York: Routledge.

[5] Diener, E., \& Ryan, K. (2009). Subjective well-being: a general overview. South African Journal of Psychology, 39(4), 391-406.

[6] CPMH UGM, PMI, Norwegian Red Cross, International Federation and Red Cross and Red Crescent Societies. (2011). Final Report of Need Assessment for the Youth Mental Health and Character Building Program.

[7] Wells, J., Barlow, J., and Stewart-Brown, S. (2003), "A systematic review of universal approaches to mental health promotion in schools", Health Education, Vol. 103, 4 pp. 197 -220 .

[8] Keyes, C.L.M. 2003. Complete mental health: An agenda for 21 st century in Keyes, Corey L. M \& Haidt, Jonathan (Editors). Flourishing Psychology and the Life Well-lived. Washington DC: APA.

[9] Kumara, A. (2012). Kesehatan Mental di Sekolah. In Faturochman, Minza, W.M., and Lufityanto, G. (eds). Psikologi untuk Kesejahteraan Masyarakat. Yogyakarta: Pustaka Pelajar.
[10] Kumara, A., Hidayat, I., Fairuz, Kurniawati, D., Iswari, R. D., and Rulanggi, R. (2013). Social Adjustment and Mental Health of 6 Grade Students - 12 Grade High School Students, Research Report.

[11] Lazarus, R. S., \& Folkman, S. (1984). Stress, coping and appraisal. New York: Springer

[12] Leibson, C. L., Katusic, S. K., Barbaresi, W. J., Ransom, J., \& O'brien, P. C. (2001). Use and costs of medical care for children and adolescents with and without attention-deficit/hyperactivity disorder. Jama, 285(1), 60-66.

[13] Santrock, J. W. (2003). Adolescence ( $9^{\text {th }}$ Edition). New York: Mc Graw Hill

[14] Singh, K., \& Junnarkar, M. (2015). Correlates and predictors of positive mental health for school going children. Personality and Individual Differences, 76, 82-87.

[15] BPS. (2010). Sensus Penduduk 2010. Retrieved from https://sp2010.bps.go.id

[16] Richard, C., Lussier, M-T., Gagnon, R.,. and ,Lamarche, L. (2004). GHQ-28 and cGHQ-28: implications of two scoring methods for the GHQ in a primary care setting. Soc Psychiatry Epidemiol 39 : 235-243.

[17] Riset Kesehatan Dasar. (2013). Department Kesehatan RI.

[18] Tribunnews.com. (2013). During 2013, Students Died Due to Brawls by Wahyu Aji. Downloaded at 18 April 2014 Retrieved from http://jogja.tribunnews.com/2013/11/21/selama-2013-19-pela jar-tewas-sis-sia-akibat-tawuran/.

[19] UU Republik Indonesia No 20 tahun 2003 tentang Sistem Pendidikan Nasional

[20] WHO. (2003). Caring for children and adolescence with mental disorders. Geneva: World Health Organization.

[21] WHO. (2004). Mental health policy and service guidance package: Mental Health Information Systems. Geneve: World Health Organization.

[22] WHO. (2008). The World Health Report 2008: Primary health care - Now more than ever. Geneve: World Health Organization.

[23] WHO. (2011). Mental health: a state of well-being. Retrieved from http://www.who.int/features/factfiles/mental_health/en/ on Januari 2015

[24] Wimbarti, S \& Purwantini, L. (2013). The Correlation between Conservational Ability and Mathematical Ability in Students with Mathematical Difficulties. Yogyakarta: Faculty of Psychology UGM.

[25] Wimbarti, S. \& Oktaviana, M. (2014). Clinical Validation of Strength and Difficulties Questionnaire (SDQ-TR) as a Screening Instrument Behavioral Difficulties on Children and Adolescents. Yogyakarta: Faculty of Psychology UGM.

[26] Wimbarti, S \& Siregar, J. (2014). Clinical Validation of Strength and Difficulties Questionnaire - Teacher Report (SDQ-TR) as a Screening Instrument for Hyperactivity Disorders. Yogyakarta: Faculty of Psychology UGM. 